\title{
Influence of Plant Growth Regulators on In Vitro Shoot Multiplication and Plantlet Formation in Cassia angustifolia Vahl
}

\author{
Iram Siddique ${ }^{*}$, Najat Abdullah Wahab Bukhari, Kahkashan Perveen and Iffat Siddiqui \\ Department of Botany and Microbiology; College of Science, Female Centre for Scientific and Medical Colleges; \\ King Saud University - Kingdom of Saudi Arabia
}

\begin{abstract}
An effective and improved plant regeneration system was successfully developed using shoot tip explants taken from a two years old mature plant of Cassia angustifolia. The effect of different cytokinins, [6-benzyladenine (BA), Kinetin (Kin) and thidiazuron (TDZ)] at different concentrations (0.5-10 $\mu M)$ were evaluated as augmented with Murashige and Skoog (MS 1962) medium. Among all the cytokinins tested, TDZ (5.0 $\mu M)$ was optimum in inducing multiple shoots as compared to BA and Kin. The rate of shoot multiplication was increased when optimal concentration (5.0 $\mu \mathrm{M})$ of BA and Kin was tested with different concentration (0.1-1.0 $\mu \mathrm{M})$ of Indole-3-acetic acid (IAA). Among all the combinations tested, the maximum rate of shoot multiplication was obtained on MS medium supplemented with $5.0 \mu \mathrm{M} \mathrm{BA}$ and $0.5 \mu \mathrm{M}$ IAA. The number of the shoots and shoot length developed in TDZ was increased when transferred to MS medium devoid of TDZ. After every subculture, rate of the shoot multiplication and shoot length showed increment and continued even after fifth subculture without any decline rate. In vitro rooting in regenerated shoots were best obtained in half-strength MS medium supplemented with $2.0 \mu M$ indole-3butyric acid (IBA). Plantlets with well-developed shoot and roots were successfully hardened off in earthen pots containing garden soil and grown in greenhouse with $80 \%$ survival rate.
\end{abstract}

Key words: Acclimatization, Growth regulator, Indole-3- butyric acid, Shoot tip, Senna

\section{INTRODUCTION}

Cassia angustifolia (Vahl.), well-known by its Arabian name "Senna" is an important medicinal shrub of Fabaceae family. Almost every part of this drought-resistant shrub has diverse medicinal properties and frequently administered in indigenous system of medicine in various parts of Africa and Asia for the treatment of various ailments (Srivastava et al. 2010). The presence of Sennosides A, B, C, D, Kampferol, anthraquinone, essential oil, isohamnentin and emodin in the leaves, and useful protein and water soluble polysaccharides in mature pods helps to convalesce from amoebic dysentery, splenic enlargement, jaundice, tumor bronchitis and leprosy (Anonymous 1992). Sennosidescontaining preparations are most widely used amidst a number of synthetic laxatives. The plant is one of the best for reclamation and cultivation in sandy wastelands (Sharma et al. 1999).

The shrub is heavily exploited by the pharmaceutical companies, as it is having export potential for developing countries. This not only poses threat to this plant alone but also disturbs the ecological balance, which affects a variety of organisms. High seed mortality and susceptibility of the crop to frost (Agrawal and Sardar 2007)

*Author for correspondence: siddiqueiram@gmail.com 
restricts its large-scale cultivation. Tissue culture is an alternative method, which has been successfully utilized for several medicinal plant where traditional methods seem inadequate.

Plant tissue culture has emerged as a powerful technique with the potential not only for rapid, clonal and mass propagation of the plant species required in large number in plantation programmes, but also for the conservation of important and rare ones. It also provides novel approaches for the production of the plants, which are high yielding and resistant to abiotic and biotic stresses. The technique has been widely applied in all the sectors of horticulture, plantation and forestry and has contributed significantly towards the enhanced production of high quality planting material to the market.

Some in vitro regeneration protocol are available for Cassia angustifolia through different explants by different methods, such as direct regeneration through cotyledonary node and nodal segments (Agrawal and Sardar 2003; Siddique and Anis $2007 \mathrm{a}$ and b), indirect plant regeneration via cotyledon and leaflet derived calli (Agrawal and Sardar 2006; Siddique et al. 2010) and somatic embryogenesis from cotyledon (Agrawal and Sardar 2007) but to the best of our knowledge, there is no report on direct organogenesis using shoot tip explants. Therefore, the objective of the present study was to compare the relative efficiency of shoot tip explants with previously available reports for in vitro micropropagation from different explants and to standardize the optimal concentration of cytokinin, or cytokinin and auxin combinations for maximum shoot production and establishment of complete plantlets.

\section{MATERIALS AND METHODS}

\section{Plant material and surface sterilization}

The shoot tips $(<2 \mathrm{~cm})$ excised from a two years old healthy plant of Cassia, grown in the botanical garden of the University were taken as explants. They were thoroughly washed with tap water for half an hour, followed by soaking in $5 \%(\mathrm{v} / \mathrm{v})$ solution of a detergent Labolene (Qualigens, Mumbai, India) for 5 min. Following repeated washes with sterile distilled water, the explants were surface sterilized with freshly prepared $0.1 \%$ $(\mathrm{w} / \mathrm{v})$ mercuric chloride (Qualigens, Mumbai,
India) for $5 \mathrm{~min}$, followed by repeated washing with sterile distilled water.

\section{Culture media and culture conditions}

Murashige and Skoog (MS 1962) medium with $3 \%(\mathrm{w} / \mathrm{v})$ sucrose (Qualigens, Mumbai, India) and $0.8 \%$ agar (w/v) (Sigma Aldrich Ltd, USA) was used as culture medium throughout the experiment. Different plant growth regulators, singly and in combinations were added to the medium as specified below. The $\mathrm{pH}$ of the medium was adjusted to 5.8 using $1 \mathrm{~N} \mathrm{NaOH}$ or $1 \mathrm{~N} \mathrm{HCl}$ prior to autoclaving at $121^{\circ} \mathrm{C}$ for $15 \mathrm{~min}$. All the cultures were maintained at $25 \pm 2^{\circ} \mathrm{C}$ under a 16/8 h light /dark regime, under a photo flux density of $50 \mu \mathrm{mol} \mathrm{m} \mathrm{m}^{-2} \mathrm{~s}^{-1}$ provided by the cool white fluorescent tubes ( $40 \mathrm{~W}$, Phillips, India) and at $55 \pm 5 \%$ relative humidity.

\section{Multiple shoot induction and proliferation}

For multiple shoot induction, shoot tip explants were placed on MS medium supplemented with BA, Kin and TDZ at $0.5,2.5,5.0,7.5$ or $10.0 \mu \mathrm{M}$ either singly, or in combination with indole-3acetic acid (IAA) $(0.1,0.5$ or $1.0 \mu \mathrm{M})$. Data for shoot induction and multiplication were recorded after four and eight weeks of inoculation.

\section{In vitro rooting}

Elongated healthy shoots $(3-4 \mathrm{~cm})$ were excised and cultured on root induction media comprising full and half-strength MS medium augmented with IBA at different concentrations $(0.5,1.0,1.5$ or 2.0 $\mu \mathrm{M})$. Data were recorded on percentage of rooting, number and length of roots after four weeks of culture.

\section{Hardening and acclimatization}

Plantlets with well-developed shoot $(5-6 \mathrm{~cm})$ and roots $(4-5 \mathrm{~cm})$ were removed from the culture medium and washed thoroughly in running tap water. They were then transferred to plastic pots containing sterile soilrite (Keltech Pvt. Ltd, Bangalore, India) under diffuse light (16/8 h photoperiod) conditions. Potted plantlets were covered with transparent plastic bags to ensure high humidity and watered every three days with half-strength MS salt solution for two weeks. Plastic bags were opened after two weeks in order to acclimatize the plants to field conditions. After four weeks, acclimatized plants were transferred to the pots containing normal garden soil and 
maintained in greenhouse under normal day length conditions.

\section{Statistical analysis}

All the experiments were repeated three times and each treatment consisted twenty replicates. Oneway analysis of variance (ANOVA) was used to quantify the effect of different treatment and means were compared by Duncan's multiple range tests at 5\% level of significance.

\section{RESULTS AND DISCUSSION}

\section{Induction and multiplication phase}

No shoot induction was recorded when shoot tip explants were inoculated on growth regulator free MS medium. However, a differential response of the shoot tip explants to different cytokinins- BA, TDZ and Kin $(0.5-10 \mu \mathrm{M})$ augmented with MS medium were observed for multiple shoot induction (Table 1). The frequency of shoot induction, numbers of shoots, and shoot length per explant increased gradually with an increase in cytokinin concentration from $0.5-5.0 \mu \mathrm{M}$; after that a decrease in the rate was observed. Among the three cytokinins tested at different concentrations, $5.0 \mu \mathrm{M}$ TDZ was more effective than BA and Kin as it induced maximum percent regeneration $(88 \%)$, number of shoots $(7.0 \pm 0.89)$ and shoot length $(4.1 \pm 0.23 \mathrm{~cm})$. At the same concentration, BA induced $5.3 \pm 0.26$ shoots in $80 \%$ cultures, while Kin produced $3.6 \pm 0.35$ shoots with $71 \%$ regeneration frequency (Table 1 ). The stimulating effect of TDZ on multiple shoot formation has been reported earlier for different medicinal plant species (Sivenesan et al. 2011; Guo et al. 2011; Grabkowska et al. 2014; Singh and Dwivedi 2014). All regenerated shoots were free from any basal callusing.

Table 1 - Effect of plant growth regulators on shoot regeneration from shoot tip explants of Cassia angustifolia in MS medium after four weeks of culture.

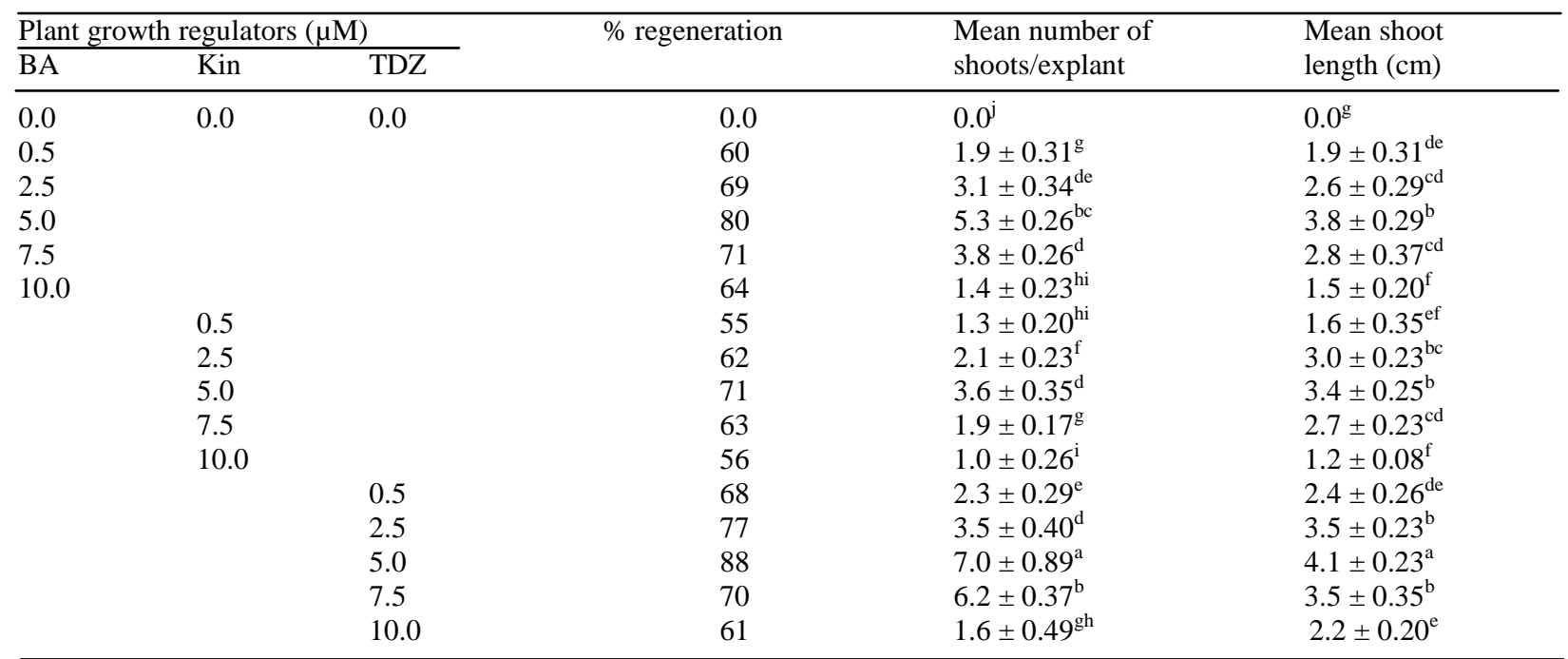

Values represent means \pm SE. Means followed by the same letter within columns are not significantly different $(\mathrm{P}=0.05)$ using Duncan's multiple range test.

To see the synergistic effect of cytokinin and auxin combinations on shoot multiplication, IAA at different concentrations $(0.1,0.5$ or $1.0 \mu \mathrm{M})$ was tested with MS medium supplemented with optimal concentration $(5.0 \mu \mathrm{M})$ of $\mathrm{BA}$ and Kin (Table 2). Addition of the IAA with cytokinin stimulated the production of new shoots with welldeveloped leaves during the subculture. The maximum number of shoots $(8.7 \pm 0.43)$ and shoot length $(5.6 \pm 0.20 \mathrm{~cm})$ per explant was obtained at $5.0 \mu \mathrm{M}$ BA and $0.5 \mu \mathrm{M}$ IAA among all cytokinin- auxin combinations and this was considered to be optimal growth regulator combination for shoot multiplication in all BA, Kin and IAA combinations. This was in consistent with other studies where BA and IAA promoted the proliferation and multiplication of the shoots in number of plants (Randive 2013; Remya et al. 2013; Skala et al. 2014). The same concentration and combination of Kin with IAA produced $7.6 \pm$ 0.60 shoots with $4.8 \pm 0.35 \mathrm{~cm}$ shoot length. 
Table 2 - Effect of different concentrations of IAA with optimal concentration of BA and Kin $(5.0 \mu \mathrm{M})$ on shoot multiplication and elongation from shoot tip explants of Cassia angustifolia in MS Medium after eight weeks of culture.

\begin{tabular}{lll}
\hline $\begin{array}{l}\text { Plant growth regulators } \\
(\mu \mathrm{M})\end{array}$ & $\begin{array}{l}\text { Mean number of } \\
\text { shoots/explant }\end{array}$ & $\begin{array}{l}\text { Mean shoot } \\
\text { length }(\mathrm{cm})\end{array}$ \\
\hline BA $(5.0)+$ IAA $(0.1)$ & $5.9 \pm 0.20^{\mathrm{d}}$ & $4.4 \pm 0.29^{\mathrm{bc}}$ \\
BA (5.0) + IAA $(0.5)$ & $8.7 \pm 0.43^{\mathrm{a}}$ & $5.6 \pm 0.20^{\mathrm{a}}$ \\
BA (5.0) + IAA (1.0) & $6.9 \pm 0.53^{\mathrm{c}}$ & $3.8 \pm 0.32^{\mathrm{d}}$ \\
Kin $(5.0)+$ IAA $(0.1)$ & $4.5 \pm 0.55^{\mathrm{de}}$ & $4.0 \pm 0.17^{\mathrm{c}}$ \\
Kin $(5.0)+$ IAA $(0.5)$ & $7.6 \pm 0.60^{\mathrm{b}}$ & $4.8 \pm 0.35^{\mathrm{b}}$ \\
Kin $(5.0)+$ IAA $(1.0)$ & $5.9 \pm 0.71^{\mathrm{d}}$ & $3.5 \pm 0.35^{\mathrm{d}}$ \\
\hline
\end{tabular}

Values represent means \pm SE. Means followed by the same letter within columns are not significantly different $(P=0.05)$ using Duncan's multiple range test.

Shoots induced from the shoot tip explants on TDZ containing medium showed problem in elongation when continued to be culture on the same medium beyond a definite induction time (Mok et al. 1982). Stimulation of the shoots production but inhibition of their elongation could be related with high cytokinin activity of TDZ. The problem of shoot elongation was overcome by the transfer of shoot clusters to secondary medium lacking TDZ where the multiple shoots elongated further within four weeks of subculture. Subculturing had a significant role on shoot proliferation. To see the effect of subculture passages on shoot multiplication, the shoots induced in MS medium supplemented with TDZ were subcultured to MS basal medium without TDZ. The cultures grown continuously on TDZ containing medium formed fasciated and distorted shoots. The deleterious effect of continued presence of TDZ on the growth and multiplication has been reported in several medicinal plants (Ahmad et al. 2006; Siddique et al. 2013). In the present study, the number of shoots per explant $(12.0 \pm 0.9)$ and shoot length $(6.9 \pm 0.29 \mathrm{~cm})$ continued to increase through the fifth subculture passages without any sign of decline (Fig. 1). Similar results were recorded by Tiwari et al. (2001) and Siddique and Anis (2007c).

\section{Rooting of microshoots}

For rooting, microshoots $(3-4 \mathrm{~cm})$ were excised from proliferated cultures and transferred to fulland half-strength MS medium supplemented with different concentration of IBA $(0.5,1.0,1.5$ or 2.0 $\mu \mathrm{M})$ (Table 3). Half-strength MS medium was superior to the full-strength MS medium and $1 / 2$ MS medium supplemented with $2.0 \mu \mathrm{M}$ IBA produced $5.4 \pm 0.20$ roots in $83 \%$ cultures after four weeks of culture. The effectiveness of IBA for rooting has also been reported in Balanites aegyptiaca (Anis et al. 2010) and Ocimum basilicum (Siddique and Anis 2007c).

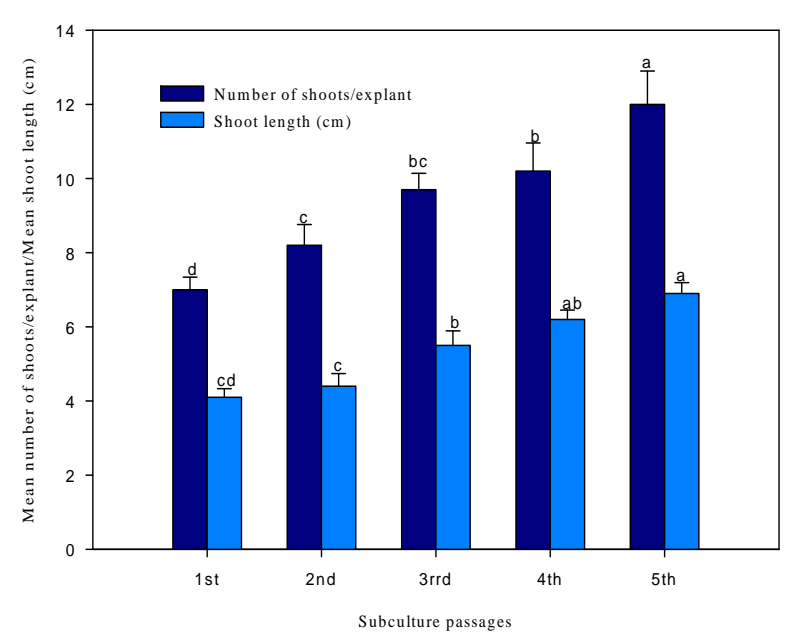

Figure 1 - The evaluation of morphogenetic effect of TDZ $(5.0 \mu \mathrm{M})$ on shoot culture after being tested for five subculture passages on growth regulator free MS medium. Bars represent mean \pm SE. Means followed by the same letter are not significantly different $(\mathrm{P}=0.05)$ using Duncan's multiple range test.

\section{Acclimatization}

Plantlets with 4-6 fully expanded leaves and welldeveloped roots were successfully hardened off inside the culture room using sterile soilrite for four weeks and were eventually established in natural soil. About $80 \%$ of the micropropagated plants survived, following the transfer from soilrite to natural soil and did not show any detectable variation. 
Table 3 - Effect of MS strength and IBA concentration on root induction from in vitro raised shoots of $C$. angustifolia after four weeks of culture.

\begin{tabular}{|c|c|c|c|}
\hline Treatment & $\%$ Rooting & $\begin{array}{l}\text { Mean no. of roots } \\
\text { /shoot }\end{array}$ & $\begin{array}{l}\text { Mean root } \\
\text { length }(\mathrm{cm})\end{array}$ \\
\hline MS & 60 & $1.8 \pm 0.11^{\mathrm{d}}$ & $1.2 \pm 0.14^{\mathrm{d}}$ \\
\hline$(1 / 2) \mathrm{MS}$ & 65 & $3.1 \pm 0.14^{\mathrm{c}}$ & $2.0 \pm 0.12^{\mathrm{cd}}$ \\
\hline$(1 / 2) \mathrm{MS}+\mathrm{IBA}(0.5 \mu \mathrm{M}) 70$ & & $3.5 \pm 0.17^{\mathrm{c}}$ & $2.8 \pm 0.17^{\mathrm{c}}$ \\
\hline$(1 / 2) \mathrm{MS}+\mathrm{IBA}(1.0 \mu \mathrm{M}) 75$ & & $4.0 \pm 0.23^{b}$ & $3.0 \pm 0.29^{b}$ \\
\hline$(1 / 2) \mathrm{MS}+$ IBA $(1.5 \mu \mathrm{M}) 79$ & & $4.2 \pm 0.27^{\mathrm{b}}$ & $3.6 \pm 0.17^{\mathrm{ab}}$ \\
\hline$(1 / 2) \mathrm{MS}+\mathrm{IBA}(2.0 \mu \mathrm{M}) 83$ & & $5.4 \pm 0.20^{\mathrm{a}}$ & $4.0 \pm 0.20^{\mathrm{a}}$ \\
\hline
\end{tabular}

Values represent means \pm SE. Means followed by the same letter within columns are not significantly different $(\mathrm{P}=$ $0.05)$ using Duncan's multiple range test.

\section{CONCLUSION}

To conclude, the present study developed a rapid and effective method for mass propagation and multiplication of this potential drug plant that could be used for secondary metabolite extraction and genetic transformation studies.

\section{ACKNOWLEDGEMENT}

The authors would like to extend their sincere appreciation to the Deanship of Scientific Research at King Saud University for funding this Research group NO. (RG\# VPP-066).

\section{REFERENCES}

Agrawal V, Sardar PR. In vitro organogenesis and histomorphological investigations in Senna (Cassia angustifolia) - medicinally valuable shrub. Physiol Mol Biol Plants. 2003; 9: 131-140.

Agrawal V, Sardar PR. In vitro propagation of Cassia angustifolia (Vahl.) through leaflet and cotyledon derived calli. Biol Plant. 2006; 1: 118-122.

Agrawal V, Sardar PR. In vitro regeneration through somatic embryogenesis and organogenesis using cotyledons of Cassia angustifolia Vahl. In Vitro Cell Dev Biol Plants. 2007; 43: 585-592.

Ahmad N, Siddique I, Anis M. Improved plant regeneration in Capsicum annuum L. from nodal segments. Biol Plant. 2006; 50: 701-704.

Anis M, Varshney A, Siddique I. In vitro clonal propagation of Balanites aegyptiaca (L.) Del. Agro Systems. 2010; 78: 151-158.

Anonymous. The wealth of India: a dictionary of Indian raw materials and industrial products. CSIR, New Delhi, 1992; Vol 3: pp 354-363.
Grabkowska R, Sitarek P, Wysokinska H. Influence of thidiazuron (TDZ) pretreatment of shoot tips on shoot multiplication and ex vitro acclimatization of Harpagophytum procumbens. Acta Physiol Plant. 2014; 36: 1661-1672.

Guo B, Abbasi BH, Zeb A, Xu LL, Wei YH. Thidiazuron: a multi-dimensional plant growth regulator. Afr J Biotechnol. 2011; 10: 8984-9000.

Mok MC, Mok DWS, Armstrong DJ, Shudo K, Isogai $\mathrm{Y}$, Okamoto T. Cytokinin activity of N-phenyl-N1,2,3-thiadiazol-5-ylurea (thidiazuron). Phytochem. 1982; 21:1509-1511.

Murashige T, Skoog F. A revised medium for rapid growth and bioassays with tobacco tissue culture. Physiol Plant. 1962; 15: 473-497.

Randive SD. In vitro micropropagation of Enicostema axillare. Adv Appl Sci Res. 2013; 4: 321-324.

Remya M, Bai VN, Mutharaian VN. In vitro regeneration of Aristolochia tagala and production of artificial seeds. Biol Plant. 2013; 57: 210-218

Sharma AK, Goya K, Gupta JP. Senna the best choice for sandy wastelands. Indian Farming. 1999; 6: 1820.

Singh P, Dwivedi P. Two-stage culture procedure using thidiazuron for efficient micropropagation of Stevia rebaudiana, an anti-diabetic medicinal herb. Biotech. 2014; 4: 431-437.

Siddique I, Bukhari NA, Perveen K, Siddiqui I, Anis M. Pre-culturing of nodal explants in thidiazuron supplemented liquid medium improves in vitro shoot multiplication of Cassia angustifolia. Acta Biol Hung. 2013; 64: 377-384.

Siddique I, Anis M. High frequency multiple shoot regeneration and plantlet formation in Cassia angustifolia (Vahl) using thidiazuron. Med Arom Plant Sci Biotechnol. 2007a; 1: 282-284.

Siddique I, Anis M. In vitro shoot multiplication and plant regeneration from nodal explants of Cassia angustifolia (Vahl): a medicinal plant. Acta Physiol Plant. 2007b; 29: 233-238. 
Siddique I, Anis M. Rapid micropropagation of Ocimum basilicum using shoot tip explants precultured in thidiazuron supplemented liquid medium. Biol Plant. 2007c; 51: 787-790.

Siddique I, Anis M, Aref IM. In vitro adventitious shoot regeneration via indirect organogenesis from petiole explants of Cassia angustifolia Vahl. a potential medicinal plant. Appl Biochem Biotechnol. 2010; 162: 2067-2074.

Sivanesan I, Song JY, Hwang SJ, Jeong BR. Micropropagation of Cotoneaster wilsonii Nakai-a rare endemic ornamental plant. Plant Cell Tiss Organ Cult. 2011; 105: 55-63.
Skala E, Mielicki W, Wysokinska H. Tanshinones in culture of Salvia przewalskii maxim in vitro. Acta Biologica Cracoviensia Series Botanica (abreviar) 2014; 56: 104-110.

Srivastava M, Srivastava S, Rawat AKS. Chemical Standardization of Cassia angustifolia Vahl seed. Pharmacog J. 2010; 2: 554-560.

Tiwari V, Tiwari KN, Singh BD. Comparative studies of cytokinins on in vitro propagation of Bacopa monniera. Plant Cell Tiss Org Cult. 2001; 66: 9-16.

Received: May 21, 2015; Accepted: June 14, 2015. 